\title{
René Pommier, Explications littéraires
}

\section{Luigi Luison}

\section{(2) OpenEdition}

\section{Journals}

\section{Edizione digitale}

URL: http://journals.openedition.org/studifrancesi/28468

DOI: 10.4000/studifrancesi.28468

ISSN: 2427-5856

\section{Editore}

Rosenberg \& Sellier

\section{Edizione cartacea}

Data di pubblicazione: 31 décembre 2006

Paginazione: 666

ISSN: 0039-2944

\section{Notizia bibliografica digitale}

Luigi Luison, «René Pommier, Explications littéraires », Studi Francesi [Online], 150 (L | III) | 2006, online dal 30 novembre 2015, consultato il 08 novembre 2020. URL : http://journals.openedition.org/ studifrancesi/28468; DOI : https://doi.org/10.4000/studifrancesi.28468

\section{Questo documento è stato generato automaticamente il 8 novembre 2020.}

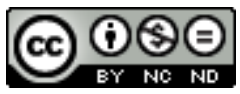

Studi Francesi è distribuita con Licenza Creative Commons Attribuzione - Non commerciale - Non opere derivate 4.0 Internazionale. 


\title{
René Pommier, Explications littéraires
}

\author{
Luigi Luison
}

\section{NOTIZIA}

RENÉ POMMIER, EXplications littéraires, vol. III, Paris, Eurédit, 2005, pp. 205.

1 Con questa terza raccolta René POMMIER si propone di esporre le caratteristiche di alcune grandi opere letterarie francesi e di alcune incongruenze riscontrate durante una dettagliata analisi di passi molto noti. Il volume si apre con uno studio incentrato sul primo passaggio del Sermon sur la mort di Bossuet, in cui lo scrittore, per far emergere meglio il carattere effimero dell'uomo, ricorda e sottolinea l'eternità di Dio attraverso una celebrazione dal carattere ridondante. L'A. si sofferma, in particolare, su questo effetto di insistenza che Bossuet ottiene non solo attraverso un gioco di assonanze e di allitterazioni, ma anche attraverso un uso particolare del ritmo, che conferisce al passaggio preso in esame una straordinaria stabilità.

2 Pommier estende la sua analisi anche all'Oraison funèbre d'Henriette d'Angleterre, la cui suddivisione generale riprende quella del Sermon sur la mort. In particolare, Pommier tende ad evidenziare, anche in questo caso, l'elemento stilistico che emerge nella prima parte, in cui Bossuet annuncia chiaramente la sua intenzione di servirsi della morte prematura di Henriette d'Inghilterra per far prendere coscienza a tutti gli uomini del vuoto delle grandezze umane e della vanità dei piaceri terreni.

Le qualità indispensabili che deve possedere una scena espositiva ed i problemi che pone, è l'argomento successivo proposto da Pommier. In tale contesto, l'attenzione dell'A. è circoscritta a un passo della Phèdre di Racine (atto I, scena I, versi 1-56). Partendo dal presupposto che tutte le scene espositive sono destinate a fornire allo spettatore le informazioni di cui ha bisogno per comprendere la pièce, l'A. evidenzia l'importanza della prima scena della tragedia raciniana, che si presenta sotto forma di dialogo tra uno dei protagonisti della pièce, Hippolyte, e il personaggio che recita il ruolo di confidente, Théramène. Analizzando dettagliatamente i cinquantasei versi, Pommier dimostra l'abilità di Racine nel fornire informazioni molto dettagliate ed 
importanti in così pochi versi, ottenendo una situazione tale in cui la verosimiglianza psicologica si accorda perfettamente con le necessità drammaturgiche.

Oltre alle pièces teatrali, Pommier prende in esame anche il genere poetico, mediante uno studio che coinvolge il sonetto Les Aveugles di Baudelaire, apparso per la prima volta nel 1860 nella rivista L'Artiste. In queste pagine, Pommier intende capire se il dipinto La Parabole des Aveugles del fiammingo Brueghel sia da considerare come fonte di ispirazione per la composizione del sonetto di Baudelaire. Pommier formula l'ipotesi che il poeta francese potrebbe, invece, aver preso ispirazione da un passaggio de $L a$ Fenêtre du coin, uno dei racconti postumi dello scrittore tedesco Hoffmann, pubblicato in francese nel 1856.

Un'altra grande opera teatrale su cui si incentra lo studio di Pommier è Le Malade Imaginaire di Molière, in particolare la scena XI dell'atto III, in cui il personaggio di Toinette, con il pretesto di provare a Béralde che Béline è profondamente attaccata a Argan, suggerisce a quest'ultimo di "fare il morto". L'A. prende in considerazione alcuni elementi molto precisi di questo passaggio, che permettono di attestare che Molière, per l'epilogo della pièce, non ha avuto bisogno di sacrificare la verosimiglianza psicologica del suo personaggio principale, sebbene le esigenze drammaturgiche e la commedia in quanto genere possano portare l'autore ad attentare alla coerenza psicologica di un personaggio. Con questa analisi, Pommier intende soprattutto mettere in discussione le osservazioni sollevate dallo studioso Robert Garapon che nel suo libro Le dernier Molière, a proposito del personaggio di Argan che accetta troppo facilmente di "simulare il morto", afferma che la necessità di sciogliere l'intrigo ha indotto Molière a fare uno strappo alla regola della verosimiglianza psicologica.

Lo studio su Candide di Voltaire, che chiude il volume, si sofferma su alcune piccole incongruenze rilevate da Pommier, il quale dimostra come la redazione volteriana sia stata molto veloce ed il lavoro di correzione un po' affrettato. Nel caso specifico, Pommier si riferisce alla piccola anomalia contenuta all'inizio del capitolo terzo, nella celebre evocazione della guerra tra i Bulgari e gli Arabi. L'anomalia riguarda il censimento dei soldati uccisi nella battaglia. Durante lo scontro (suddiviso in tre fasi: duello d'artiglieria, fuoco di fanteria e carica con la baionetta), che riproduce lo schema tipo di una battaglia del XVIII secolo, l'ammontare delle perdite indicate da Voltaire è di trentamila uomini. Pommier, calcolando le perdite indicate da Voltaire nelle singole fasi della battaglia, rileva che il totale ammonterebbe tra le ventiquattromila e le ventottomila vittime. Ne consegue, quindi, una differenza di qualche migliaio di vittime. La disattenzione di Voltaire, secondo Pommier, risiederebbe dunque in un calcolo affrettato delle perdite umane delle singole fasi della battaglia. 